\title{
Preface to the MME Special Focus Issue on Tailings Management
}

\author{
Kimberly Finke Morrison ${ }^{1}$
}

Published online: 12 May 2021

(C) Society for Mining, Metallurgy \& Exploration Inc. 2021

Tailings are a waste product of the mining process. Described simplistically, material excavated from the mine is categorized as either ore or waste, and waste is generally hauled to a waste rock storage facility while ore is hauled or conveyed to a mill and plant for processing. Ore is processed to extract a desired commodity and the remaining material is considered tailings, which also includes any chemical additives and water that may have been used during processing. Water may be recovered from the tailings and recirculated through the process plant prior to transporting the tailings to a tailings storage facility (TSF) or using the tailings as backfill for underground mine voids.

Only a few percent of the ore tonnage that is processed for base metals results in a desired commodity, with the larger portion of the tonnage becoming tailings. Worldwide production of tailings increases with every decade. Mining operations in the late 1800 s and early 1900 s produced only about 1 to 100 metric tons per day, while modern mining operations can produce one million metric tons per day. Rising public demand for commodities supports the increasing mine production and associated tailings production rates. An increase in tailings production also increases the potential for environmental, economic, and social impacts during the construction, operation, and closure of a TSF and can increase the technical complexity of tailings transport and deposition. Easy-toobtain resources are being depleted, and mining operations are being forced to go deeper and process lower-grade ores.

In a keynote address at the 2011 Tailings and Mine Waste Conference held in Vancouver, British Columbia, Andy Robertson described the trend of increasing ore production, decreasing grades, and increasing tailings production where "every 30 years, the volume of water and tailings produced by the industry increases tenfold" [3]. Robertson stated

Kimberly Finke Morrison

Kim.Morrison@newmont.com

1 Newmont Corporation, Denver, CO, USA implications of this trend as elevating the risk potential for surface TSFs by a factor of 20 for every one-third century, as ever larger and higher TSFs are required to store the quantity of tailings produced by mining lower ore grades.

The trend of increasing tailings production has also resulted in the construction of larger surface TSFs and increases in the number of incidents and severity of consequences associated with facility failure. Since 2001, surface TSF failures have occurred at a rate of approximately two facilities per year, with the failure rate having increased further for the last five years. With each failure, stakeholders, including the public, regulators, investors, and owners, grow more cautious of tailings management practices. On January 25, 2019, Dam I at the Córrego do Feijão iron ore mine near Brumadinho, Brazil, failed with catastrophic consequences, rapidly shaping the way the industry, its investors, and its insurers view tailings dam safety. Regulations in Brazil were changed nearly overnight, while the failure had further reaching effects. Of note, the International Council on Mining and Metals (ICMM), the United Nations Environment Programme (UNEP), and the Principles for Responsible Investment (PRI) co-convened an independent Global Tailings Review (GTR) in March 2019 to establish an international standard for TSFs. Compliance with the Global Industry Standard on Tailings Management (GISTM), which was published on August 5, 2020, is an ICMM member company commitment, with greater uptake encouraged by the industry as a whole.

Water has been a common influence in failure modes for TSFs worldwide, and the trend toward increasingly dewatered tailings is expected to continue. The independent expert review panel for the Mount Polley TSF stated [2]: "Improving technology to ensure against failures requires eliminating water both on and in the tailings: water on the surface, and water contained in the interparticle voids. Only this can provide the kind of failsafe redundancy that prevents releases no matter what. ... Simply put, dam failures are reduced by reducing the number of dams that can fail. Thus, the path to zero leads to best practices, then continues on to best technology." Further to this, they concluded that the "future requires not only an 
adoption of best applicable practices, but also a migration to best available technology," such as filtered, unsaturated, compacted tailings and elimination of long-term water covers. Dewatering technologies are responding to this trend and advancing toward efficiently removing water at higher production rates and capacities for a broad range of tailings products.

The GISTM [1] further encourages use of improved technologies for tailings management, with the word "technologies" used five times within the 77 requirements. Requirement 6.6 states that operators shall "include new and emerging technologies and approaches and use the evolving knowledge in the refinement of the design, construction and operation of the tailings facility" [1].

As long as we have mining and mineral processing, tailings and the responsible management thereof will remain at the forefront with a company's environmental, social, and governance (ESG) performance; in part, a reflection of how well tailings risks are being managed. The focus of this special issue on tailings management is on research and technology. Specific topics covered include the following: improving the understanding of in-place tailings characteristics; enhancements to filtration technologies; co-mingling of tailings with waste rock to improve in-place characteristics; tailings management planning and deposition systems; and understanding geotechnical failure mechanisms for conventional TSFs to support improvements to performance-based monitoring strategies.

Special-issue Guest Editor,

Kimberly Finke Morrison, P.E., R.G.

\section{References}

1. GTR (Global Tailings Review) (2020) Global Industry Standard on Tailings Management. https:/globaltailingsreview.org/wp-content/ uploads/2020/08/global-industry-standard_EN.pdf

2. Morgenstern NR, Vick SG, van Zyl D (2015) Independent expert engineering investigation and review panel: report on Mount Polley tailings storage facility breach. Province of British Columbia, Victoria www.mountpolleyreviewpanel.ca/final-report

3. Robertson A (2011) Mine waste management in the 21st centurychallenges and solutions beyond incremental changes. Tailings and Mine Waste 2011: Proceedings of the International Conference on Tailings and Mine Waste. University of British Columbia, Vancouver

Publisher's Note Springer Nature remains neutral with regard to jurisdictional claims in published maps and institutional affiliations. 